\title{
Comparação florística de florestas inundáveis das regiões Sudeste e Sul do Brasil
}

\author{
ANA CAROLINA DA SILVA ${ }^{1,4}$, EDUARDO VAN DEN BERG ${ }^{2}$, PEDRO HIGUCHI ${ }^{3}$ e ARY \\ TEIXEIRA DE OLIVEIRA FILHO ${ }^{1}$
}

(recebido: 13 de abril de 2006; aceito: 12 de abril de 2007)

\begin{abstract}
Floristic comparison of wetland forests in Southeast and South Brazil). This study evaluated the variation of tree species composition of 35 wetland forest areas in Southeast and South Brazil. The analysis of the floristic composition was based on a floristic checklist containing 602 species of 23 alluvial forests (seasonally inundated) and 12 swamp forests (permanently waterlogged). The species were classified, using a $\chi^{2}$ test, according to the habitat preference in: 1 ) swamp forest species, e.g. Magnolia ovata (A. St.-Hil.) Spreng., Dendropanax cuneatus (DC.) Decne \& Planch. and Calophyllum brasiliense Cambess.; 2) alluvial forest species, e.g. Sebastiania commersoniana (Baill.) L.B. Sm. \& Downs, Ocotea pulchella Mart. and Sorocea bonplandii (Baill.) W. Burger et al. and 3) non preferential species, e.g. Luehea divaricata Mart. \& Zucc., Syagrus romanzoffiana (Cham.) Glassman and Copaifera langsdorffii Desf. Multivariate gradient analysis (Detrended Correspondence Analysis) showed higher clustering of swamp forest areas than aluvial forest areas, indicating close florist similarity in the first group. The results indicated that the environmental heterogeneity associated to different flood regimes is determinant in defining the phytogeographic patterns of wetland forest areas.
\end{abstract}

Key words - alluvial forest, floristics, multivariate analysis, swamp forest

RESUMO - (Comparação florística de florestas inundáveis das regiões Sudeste e Sul do Brasil). Este estudo avaliou a variação da composição florística do componente arbóreo de 35 áreas inundáveis das regiões Sul e Sudeste do Brasil. Foi utilizada uma lista com 602 espécies arbóreas de 23 áreas de florestas aluviais (inundações temporárias) e 12 de florestas paludosas (inundações permanentes). Por meio de um teste de $\chi^{2}$, as espécies foram classificadas de acordo com o habitat em: 1) preferenciais de florestas paludosas, e.g. Magnolia ovata (A. St.-Hil.) Spreng., Dendropanax cuneatus (DC.) Decne \& Planch. e Calophyllum brasiliense Cambess.; 2) preferenciais de florestas aluviais, e.g. Sebastiania commersoniana (Baill.) L.B. Sm. \& Downs, Ocotea pulchella Mart. e Sorocea bonplandii (Baill.) W. Burger et al. e 3) espécies não preferenciais, e.g. Luehea divaricata Mart. \& Zucc., Syagrus romanzoffiana (Cham.) Glassman e Copaifera langsdorffii Desf. A análise multivariada de gradientes (DCA) demonstrou maior agrupamento das florestas paludosas do que florestas aluviais, indicando maior heterogeneidade florística do último grupo. Os resultados indicaram que a variação, ambiental associada aos diferentes regimes de inundação é determinante na definição dos padrões fitogeográficos de áreas inundáveis.

Palavras-chave - análise multivariada, floresta aluvial, floresta paludosa, florística

\section{Introdução}

Estima-se que na América do Sul, cuja precipitação anual máxima varia de 1.000 a $5.000 \mathrm{~mm}$, bem distribuída ou não durante o ano, cerca de $2.000 .000 \mathrm{~km}^{2}$, ou seja, $20 \%$ da área total estão sujeitos a alagamentos nos períodos de chuva mais intensos (Junk 1993). Estas áreas ocorrem predominantemente em margens de rios e lagos, ou locais em que o lençol freático é aflorante, e

\footnotetext{
1. Universidade Federal de Lavras, Departamento de Ciências Florestais, 37200-000 Lavras, MG, Brasil.

2. Universidade Federal de Lavras, Departamento de Biologia, 37200-000 Lavras, MG, Brasil.

3. Universidade do Estado de Santa Catarina, Centro de Ciências Agroveterinárias, Av. Luiz de Camões, 2090, B. Conta Dinheiro, 88520-000 Lages, SC, Brasil.

4.
}

apresentam os padrões florístico e estrutural da vegetação determinados pelo clima, por fatores edáficos relacionados à qualidade dos sedimentos e da água (Rodrigues \& Shepherd 2000), pela vegetação do entorno como fonte de propágulos (Ivanauskas et al. 1997, Rodrigues \& Shepherd 2000), pelas ações antrópicas e também pela influência de fatores associados à periodicidade (Junk 1993), duração (Junk 1993, Lobo \& Joly 2000) e profundidade do alagamento (Junk 1993).

A vegetação arbórea que ocorre nestas áreas pode ser divida, de acordo com o regime de inundação, em florestas aluviais e florestas paludosas. De acordo com Lobo \& Joly (2000), a inundação temporária em florestas aluviais pode durar algumas horas ou poucos dias sobre os diques ou ser de longa duração nas áreas de depressão atrás dos diques, enquanto que nas florestas paludosas, os solos hidromórficos 
permanecem hidricamente saturados na maior parte do ano e o encharcamento se torna menos evidente apenas no inverno. Estas diferenças na duração do período de alagamento causam variações na fisionomia e composição florística das áreas (Schiavini 1992), assim como na densidade, na dominância, na freqüência e na estrutura das populações de plantas (Walter \& Ribeiro 1997).

As mudanças do padrão florístico e estrutural da vegetação de áreas inundáveis ocorrem em função da heterogeneidade ambiental associada ao regime de inundação como, por exemplo, diferentes níveis de oxigenação do solo e padrões de sedimentação. A eliminação do ar no solo limita as trocas gasosas entre as plantas e a atmosfera, criando, assim, um ambiente hipóxico ou anóxico, que exerce caráter fortemente seletivo no processo de evolução das espécies (Ivanauskas et al. 1997, Lobo \& Joly 2000). Além disso, associada às inundações, ocorre deposição periódica de sedimentos, fator limitante ao estabelecimento das plantas (Junk 1993), pois pode inibir a germinação de sementes e aumentar a mortalidade de plântulas. Plantas e animais que vivem nessas áreas respondem ao alagamento por meio de adaptações morfológicas, anatômicas, fisiológicas e etológicas e, assim, as áreas alagadas podem ser consideradas importantes nos processos de especiação, contribuindo para a geração de diversidade de espécies (Junk 1993).

Considerando a grande extensão geográfica de ambientes sujeitos ao alagamento e sua importante contribuição para a biodiversidade, análises florísticas comparativas entre diferentes áreas são de grande importância para a definição de padrões fitogeográficos. Recentemente, vários estudos com esta abordagem foram realizados (Oliveira Filho \& Ratter 2000, Rodrigues \& Nave 2000, Oliveira Filho \& Fontes 2001, Oliveira Filho et al. 2005), entretanto, em se tratando de florestas inundáveis, pouco se conhece sobre os padrões de distribuição de espécies nestes ambientes, o que reforça a necessidade do presente estudo.

Dessa forma, este estudo avaliou a variação da composição florística do componente arbóreo de 35 áreas sujeitas a inundação das regiões Sul e Sudeste do Brasil. As hipóteses do trabalho foram: a) a variação da composição florística está ligada a aspectos geográficos, como distância, bacias hidrográficas e clima e b) os diferentes regimes de inundação afetam a composição florística e as diferenças florísticas entre as áreas.

\section{Material e métodos}

Foi utilizada uma lista de espécies arbóreas compiladas de 35 levantamentos florísticos e fitossociológicos de locais sujeitos à inundação nas regiões Sudeste e Sul do Brasil (figura 1). Buscou-se utilizar levantamentos fitossociológicos e florísticos em que a circunferência mínima foi em torno de $15 \mathrm{~cm}$, embora, devido à pouca disponibilidade de estudos em áreas inundadas, seis levantamentos utilizados não seguiram o mesmo critério (tabela 1).

Em razão de a literatura apresentar diferentes nomenclaturas para áreas inundáveis, convencionou-se denominar florestas aluviais aquelas com inundações temporárias e de florestas paludosas aquelas inundadas durante todo o ano ou durante a maioria dos meses, citadas na literatura também como matas de brejo ou florestas higrófilas (Leitão Filho 1982) e, quando sobre turfeiras, matas turfosas (Waechter \& Jarenkow 1998). Matas ribeirinhas ou ciliares, quando não especificado seu caráter de inundação temporária, não foram utilizadas neste estudo, pois não são todas que possuem influencia aluvial, além dos estudos dessas matas abrangerem, muitas vezes, não somente a área de influência aluvial.

Das 35 áreas, 11 estudos foram realizados no Estado de Minas Gerais, sendo três em florestas paludosas e oito em áreas aluviais; oito trabalhos foram realizados em florestas paludosas no Estado de São Paulo; 11 trabalhos em áreas aluviais no Estado do Paraná e cinco trabalhos foram realizados no Estado do Rio Grande do Sul, um em floresta paludosa e quatro em floresta aluvial (tabela 1). Para alguns dos trabalhos cujos levantamentos florísticos incluíam áreas inundáveis e não inundáveis, foram utilizadas somente as espécies que ocorreram, de acordo com os autores, em áreas inundáveis. A lista florística foi organizada obedecendo ao sistema APG II (2003), em uma matriz binária de presença e ausência das espécies nas 35 áreas. O banco de dados passou por uma revisão para verificação de sinonímias e as grafias dos nomes dos autores foram uniformizadas seguindo-se a padronização proposta por Brummitt \& Powell (1992) sendo, em seguida, realizada uma DCA (análise de correspondência retificada), por meio do programa PC-ORD versão 4.14 (McCune \& Mefford 1999).

A riqueza de espécies das florestas aluviais e paludosas foi comparada por meio de curvas espécie-área construídas a partir de 100 permutações aleatórias (Gotelli \& Colwell 2001). Esta análise foi realizada no programa $\mathrm{R}$ versão 2.4 (R Development Core Team 2006), por meio da biblioteca Vegan (Oksanen et al. 2006).

As espécies foram classificadas de acordo com o habitat em: 1) preferenciais de florestas paludosas, que foram as espécies que ocorreram, principalmente, nas florestas paludosas; 2) preferenciais de florestas aluviais, aquelas que ocorreram preferencialmente nas florestas aluviais e 3 ) espécies não preferenciais, que foram comuns tanto em florestas paludosas como nas aluviais. Para esta classificação, foi utilizado o teste $\chi^{2}$, realizado no programa $\mathrm{R}$ versão 2.4 ( $\mathrm{R}$ 
Development Core Team 2006), com o nível de significância $(\alpha)$ de $10 \%$, representando a probabilidade que a hipótese nula (a espécie não ser preferencial) seja verdadeira. Como um dos requerimentos do teste $\chi^{2}$ é de que as freqüências observadas não sejam muito pequenas, na classificação das espécies foram consideradas apenas aquelas que ocorrem em, no mínimo, sete áreas inundáveis, que representa $20 \%$ das áreas estudadas.

\section{Resultados e Discussão}

Foram encontradas 602 espécies arbóreas nas 35 listagens analisadas, sendo que nas florestas aluviais ocorreram 510 espécies (em 23 áreas estudadas) e nas florestas paludosas 294 espécies (em 12 áreas estudadas). Quando se estima o número de espécies de 12 áreas aluviais pelo método de curva espécie-área, este número $(366,33 \pm 25,4)$ é maior que o encontrado para as 12 florestas paludosas. O menor número de espécies nas florestas paludosas pode ser explicado pelo ambiente mais seletivo, homogêneo e estável, com inundação constante durante quase todo o ano (Marques et al. 2003) e pela maior proximidade geográfica das áreas quando comparadas com as florestas aluviais. Comprovando este resultado, na DCA (figura 2), as florestas paludosas formaram um agrupamento mais coeso que as florestas aluviais, indicando maior homogeneidade florística no caso das primeiras. A exceção foi da floresta paludosa na planície costeira do Rio Grande do Sul (Wae), devido à grande distância geográfica, diferenças edáficas (está localizada em substrato arenoso de origem marinha) e de altitude em relação às outras florestas paludosas estudadas,

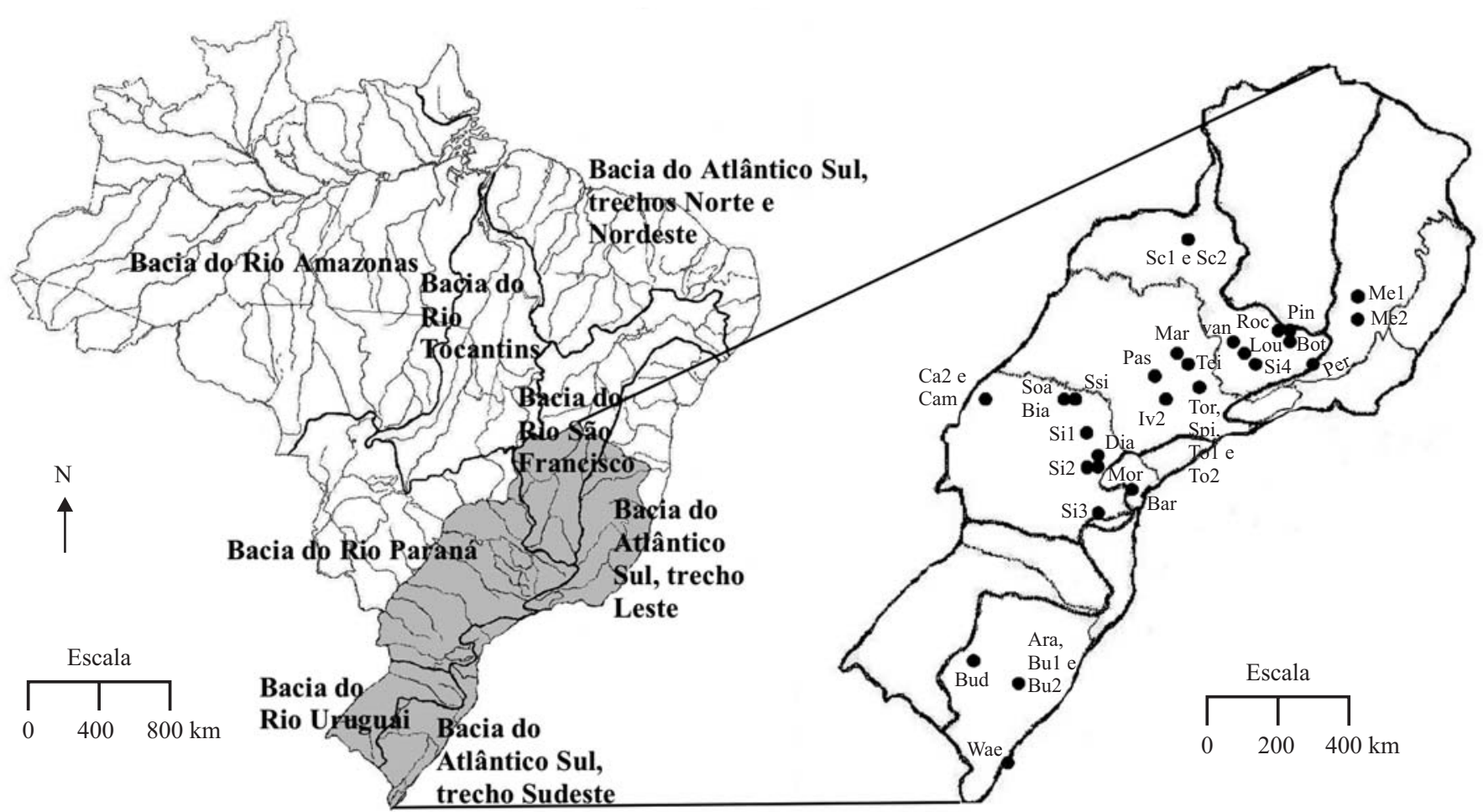

Figura 1. Localização geográfica das 35 áreas de florestas inundáveis das Regiões Sul de Sudeste do Brasil utilizadas nas análises florísticas.

Figure 1. Geographic localization of the 35 wetland forests areas in the South and Southeast Region of Brazil used for the floristic analyzes.

Sc1 = Schiavini 1992, area 1; Sc2 = Schiavini 1992, area 2; Me1 = Meira Neto et al. $1997 ;$ Me2 = Meira Neto et al. 2003; Roc $=$ Rocha et al. 2005; Pin = Pinto et al. 2005; Bot = Botrel et al. 2002; van = E. van den Berg et al . data not published; Lou = Loures 2006; Si4 = Silva 2007; Per = Pereira et al. 2006; Mar = Marques et al. 2003; Pas = Paschoal \& Cavassan 1999; Tei = Teixeira \& Assis 2005; Iv2 = Ivanauskas et al $.1997 ;$ Tor $=$ Torres et al. $1994 ; \mathrm{Spi}=$ Spina 1997; To1 = Toniato et al. 1998, area 1; To2 = Toniato et al. 1998, area 2; Ca2 = Campos et al. 2000; Cam = Campos \& Souza 2002; Soa = Soares \& Anjos 1997; Bia = Bianchini et al. 2003; Ssi $=$ Soares-Silva et al. $1992 ;$ Si1 $=$ Silva et al. 1995; Si2 = Silva et al. 1992; Dia = Dias et al. 1998; Mor = Moro et al. 2001; Bar = Barddal et al. 2004; Si3 = Silva et al. 1997; Bud $=$ Budke et al. 2004; Ara = Araújo et al. 2004; Bu1 = Budke et al. 2007; Bu2 = J.C. Budke et al . data not published; Wae $=$ Waechter \& Jarenkow 1998. 
Tabela 1. Levantamentos florísticos e fitossociológicos das áreas de florestas inundáveis analisadas, ordenados por estado. $\mathrm{Ne}=$ número de espécies amostradas; $\mathrm{CAP}=$ circunferência à altura do peito $(1,30 \mathrm{~m})$.

Table 1. Floristic and phytosociologic surveys of the analyzed wetland forests areas, sorted by state: $\mathrm{Ne}=\mathrm{Number}$ of sampled species; CAP = circumference at breast height $(1.30 \mathrm{~m})$.

\begin{tabular}{|c|c|c|c|c|c|c|c|c|c|}
\hline \multirow[t]{2}{*}{ Autores } & \multirow[t]{2}{*}{ Sigla } & \multicolumn{2}{|c|}{ Local de estudo } & \multirow{2}{*}{$\begin{array}{l}\text { Altitude } \\
\text { média }(\mathrm{m})\end{array}$} & \multirow[b]{2}{*}{ Habitat } & \multirow{2}{*}{$\begin{array}{l}\text { Método de } \\
\text { amostragem }\end{array}$} & \multirow{2}{*}{$\begin{array}{c}\text { Área } \\
\text { amostrada }\end{array}$} & \multirow{2}{*}{$\begin{array}{c}\text { Critério de } \\
\text { inclusão }\end{array}$} & \multirow[b]{2}{*}{$\mathrm{Ne}$} \\
\hline & & Município & Estado & & & & & & \\
\hline $\begin{array}{l}\text { Botrel et al. } \\
(2002)\end{array}$ & Bot & Ingaí & $\mathrm{MG}$ & 880 & Aluvial & Parcelas & 0,24 ha & $\begin{array}{c}\mathrm{CAP} \geq \\
15,71 \mathrm{~cm}\end{array}$ & 90 \\
\hline $\begin{array}{l}\text { Meira Neto et } \\
\text { al.(1997) }\end{array}$ & Me1 & $\begin{array}{l}\text { Ponte } \\
\text { Nova }\end{array}$ & MG & 426 & Aluvial & Quadrantes & $\begin{array}{c}100 \\
\text { pontos }\end{array}$ & $\begin{array}{c}\mathrm{CAP} \geq 15 \\
\mathrm{~cm}\end{array}$ & 54 \\
\hline $\begin{array}{l}\text { Meira Neto et } \\
\text { al.(2003) }\end{array}$ & $\mathrm{Me} 2$ & Viçosa & MG & 725 & Aluvial & Censo & 0,175 ha & $\begin{array}{c}\mathrm{CAP} \geq 10 \\
\mathrm{~cm}\end{array}$ & 47 \\
\hline $\begin{array}{l}\text { Pereira et al. } \\
(2006)\end{array}$ & Per & $\begin{array}{l}\text { Bocaina } \\
\text { de Minas }\end{array}$ & MG & 1.135 & Aluvial & $\begin{array}{l}\text { Quadrantes } \\
\text { e parcelas }\end{array}$ & $\begin{array}{l}48 \text { pontos } \\
\text { e } 0,4 \text { ha }\end{array}$ & $\begin{array}{c}\mathrm{CAP} \geq \\
15,71 \mathrm{~cm}\end{array}$ & 81 \\
\hline $\begin{array}{l}\text { Schiavini } \\
\text { (1992, área 1) }\end{array}$ & $\mathrm{Sc} 1$ & Uberlândia & MG & 800 & Aluvial & $\begin{array}{l}\text { Quadrantes } \\
\text { e parcelas }\end{array}$ & $\begin{array}{l}42 \text { pontos } \\
\text { e } 0,3 \text { ha }\end{array}$ & $\begin{array}{c}\mathrm{CAP} \geq \\
15,71 \mathrm{~cm}\end{array}$ & 56 \\
\hline $\begin{array}{l}\text { Schiavini } \\
\text { (1992, área 2) }\end{array}$ & $\mathrm{Sc} 2$ & Uberlândia & MG & 800 & Aluvial & Parcelas & 0,3 ha & $\begin{array}{c}\mathrm{CAP} \geq \\
15,71 \mathrm{~cm}\end{array}$ & 76 \\
\hline $\begin{array}{l}\text { Silva } \\
(2007)\end{array}$ & $\mathrm{Si} 4$ & $\begin{array}{l}\text { São } \\
\text { Sebastião } \\
\text { da Bela } \\
\text { Vista }\end{array}$ & MG & 809 & Aluvial & Parcelas & $1,08 \mathrm{ha}$ & $\begin{array}{c}\mathrm{CAP} \geq \\
15,71 \mathrm{~cm}\end{array}$ & 85 \\
\hline $\begin{array}{l}\text { (E. van den } \\
\text { Berg et al. } \\
\text { dados não } \\
\text { publicados) }\end{array}$ & van & $\begin{array}{l}\text { Poços de } \\
\text { Caldas }\end{array}$ & MG & 1.259 & Aluvial & Parcelas & $1,05 \mathrm{ha}$ & $\begin{array}{c}\mathrm{CAP} \geq \\
15,71 \mathrm{~cm}\end{array}$ & 58 \\
\hline Loures (2006) & Lou & $\begin{array}{l}\text { Santa Rita } \\
\text { de Caldas }\end{array}$ & MG & 1.181 & Paludoso & Parcelas & 1,0 ha & $\begin{array}{c}\mathrm{CAP} \geq \\
15,71 \mathrm{~cm}\end{array}$ & 108 \\
\hline $\begin{array}{l}\text { Pinto et al. } \\
\text { (2005) }\end{array}$ & Pin & Lavras & MG & 920 & Paludoso & Parcelas & 1,2 ha & $\begin{array}{c}\mathrm{CAP} \geq \\
15,71 \mathrm{~cm}\end{array}$ & 35 \\
\hline $\begin{array}{l}\text { Rocha et al. } \\
(2005)\end{array}$ & Roc & Coqueiral & MG & 825 & Paludoso & Parcelas & 0,32 ha & $\begin{array}{c}\mathrm{CAP} \geq \\
15,71 \mathrm{~cm}\end{array}$ & 99 \\
\hline $\begin{array}{l}\text { Ivanauskas et } \\
\text { al.(1997) }\end{array}$ & Iv2 & Itatinga & SP & 570 & Paludoso & Censo & 1 ha & $\begin{array}{c}\mathrm{CAP} \geq 15 \\
\mathrm{~cm}\end{array}$ & 36 \\
\hline $\begin{array}{l}\text { Marques et al. } \\
\text { (2003) }\end{array}$ & Mar & Brotas & SP & 470 & Paludoso & Parcelas & 0,36 ha & $\begin{array}{c}\mathrm{CAP} \geq \\
15,71 \mathrm{~cm}\end{array}$ & 40 \\
\hline $\begin{array}{l}\text { Paschoal \& } \\
\text { Cavassan } \\
(1999)\end{array}$ & Pas & Agudos & SP & 550 & Paludoso & Parcelas & 0,22 ha & $\begin{array}{c}\mathrm{CAP} \geq 15 \\
\mathrm{~cm}\end{array}$ & 36 \\
\hline Spina (1997) & Spi & Campinas & SP & 580 & Paludoso & Florístico & - & $\begin{array}{l}\text { Indivíduos } \\
\text { arbóreos }\end{array}$ & 65 \\
\hline $\begin{array}{l}\text { Teixeira \& } \\
\text { Assis (2005) }\end{array}$ & Tei & Rio Claro & SP & 640 & Paludoso & Parcelas & 0,45 ha & $\begin{array}{c}\mathrm{CAP} \geq 15 \\
\mathrm{~cm}\end{array}$ & 44 \\
\hline $\begin{array}{l}\text { Toniato et al. } \\
\text { (1998, área 1) }\end{array}$ & To1 & Campinas & SP & 580 & Paludoso & Parcelas & 0,1 ha & $\begin{array}{c}\mathrm{CAP} \geq 10 \\
\mathrm{~cm}\end{array}$ & 33 \\
\hline $\begin{array}{l}\text { Toniato et al. } \\
\text { (1998, área 2) }\end{array}$ & To2 & Campinas & SP & 580 & Paludoso & Parcelas & 0,1 ha & $\begin{array}{c}\mathrm{CAP} \geq 10 \\
\mathrm{~cm}\end{array}$ & 41 \\
\hline $\begin{array}{l}\text { Torres et al. } \\
\text { (1994) }\end{array}$ & Tor & Campinas & SP & 660 & Paludoso & Censo & 0,87 ha & $\begin{array}{c}\mathrm{CAP} \geq \\
15,71 \mathrm{~cm}\end{array}$ & 23 \\
\hline $\begin{array}{l}\text { Barddal et al. } \\
\text { (2004) }\end{array}$ & Bar & Araucária & PR & 875 & Aluvial & Parcelas & 0,2 ha & $\begin{array}{c}\mathrm{CAP} \geq 15 \\
\mathrm{~cm}\end{array}$ & 27 \\
\hline $\begin{array}{l}\text { Bianchini et } \\
\text { al.(2003) }\end{array}$ & $\mathrm{Bia}$ & Londrina & PR & 550 & Aluvial & Parcelas & 0,5 ha & $\begin{array}{c}\mathrm{CAP} \geq 15 \\
\mathrm{~cm}\end{array}$ & 63 \\
\hline
\end{tabular}


continuação

\begin{tabular}{|c|c|c|c|c|c|c|c|c|c|}
\hline \multirow[t]{2}{*}{ Autores } & \multirow[t]{2}{*}{ Sigla } & \multicolumn{2}{|c|}{ Local de estudo } & \multirow{2}{*}{$\begin{array}{l}\text { Altitude } \\
\text { média }(\mathrm{m})\end{array}$} & \multirow[b]{2}{*}{ Habitat } & \multirow{2}{*}{$\begin{array}{l}\text { Método de } \\
\text { amostragem }\end{array}$} & \multirow{2}{*}{$\begin{array}{c}\text { Área } \\
\text { amostrada }\end{array}$} & \multirow{2}{*}{$\begin{array}{l}\text { Critério de } \\
\text { inclusão }\end{array}$} & \multirow[b]{2}{*}{$\mathrm{Ne}$} \\
\hline & & Município & Estado & & & & & & \\
\hline $\begin{array}{l}\text { Campos et al. } \\
(2000)\end{array}$ & $\mathrm{Ca} 2$ & Porto Rico & PR & 237 & Aluvial & Parcelas & 1,0 ha & $\begin{array}{c}\mathrm{CAP} \geq 15 \\
\mathrm{~cm}\end{array}$ & 42 \\
\hline $\begin{array}{l}\text { Campos \& } \\
\text { Souza (2002) }\end{array}$ & Cam & Porto Rico & PR & 230 & Aluvial & Parcelas & 0,45 ha & $\begin{array}{c}\mathrm{CAP} \geq 15 \\
\mathrm{~cm}\end{array}$ & 18 \\
\hline $\begin{array}{l}\text { Dias et al. } \\
\text { (1998) }\end{array}$ & Dia & Tibagi & PR & 705 & Aluvial & Parcelas & 1,0 ha & $\begin{array}{c}\mathrm{CAP} \geq \\
15,71 \mathrm{~cm}\end{array}$ & 112 \\
\hline $\begin{array}{l}\text { Moro et al. } \\
\text { (2001) }\end{array}$ & Mor & $\begin{array}{l}\text { Ponta } \\
\text { Grossa }\end{array}$ & PR & 780 & Aluvial & Quadrantes & 16 pontos & $\begin{array}{c}\text { Indivíduos } \\
\text { lenhosos }\end{array}$ & 30 \\
\hline $\begin{array}{l}\text { Silva et al. } \\
\text { (1992) }\end{array}$ & $\mathrm{Si} 2$ & Ipiranga & PR & 809 & Aluvial & Parcelas & 1,0 ha & $\begin{array}{c}\mathrm{CAP} \geq \\
15,71 \mathrm{~cm}\end{array}$ & 36 \\
\hline $\begin{array}{l}\text { Silva et al. } \\
\text { (1995) }\end{array}$ & Sil & Sapopema & PR & 738 & Aluvial & Parcelas & 1,0 ha & $\begin{array}{c}\mathrm{CAP} \geq \\
15,71 \mathrm{~cm}\end{array}$ & 116 \\
\hline $\begin{array}{l}\text { Silva et al. } \\
\text { (1997) }\end{array}$ & $\mathrm{Si} 3$ & $\begin{array}{l}\text { São } \\
\text { Mateus do } \\
\text { Sul }\end{array}$ & PR & 801 & Aluvial & Florístico & - & - & 44 \\
\hline $\begin{array}{l}\text { Soares \& } \\
\text { Anjos (1997) }\end{array}$ & Soa & Londrina & PR & 902 & Aluvial & Parcelas & 1,0 ha & $\begin{array}{c}\mathrm{CAP} \geq \\
15,71 \mathrm{~cm}\end{array}$ & 63 \\
\hline $\begin{array}{l}\text { Soares-Silva } \\
\text { et al.(1992) }\end{array}$ & Ssi & Ibiporã & PR & 484 & Aluvial & Parcelas & 1,0 ha & $\begin{array}{c}\mathrm{CAP} \geq \\
15,71 \mathrm{~cm}\end{array}$ & 92 \\
\hline $\begin{array}{l}\text { Araújo et al. } \\
\text { (2004) }\end{array}$ & Ara & $\begin{array}{l}\text { Cachoeira } \\
\text { do Sul }\end{array}$ & RS & 45 & Aluvial & Parcelas & 0,7 ha & $\begin{array}{c}\mathrm{CAP} \geq 15 \\
\mathrm{~cm}\end{array}$ & 49 \\
\hline $\begin{array}{l}\text { Budke et al. } \\
(2004)\end{array}$ & Bud & $\begin{array}{l}\text { Santa } \\
\text { Maria }\end{array}$ & RS & 138 & Aluvial & Parcelas & 1,0 ha & $\begin{array}{c}\mathrm{CAP} \geq 15 \\
\mathrm{~cm}\end{array}$ & 56 \\
\hline $\begin{array}{l}\text { Budke et al. } \\
(2007)\end{array}$ & Bu1 & $\begin{array}{l}\text { Cachoeira } \\
\text { do Sul }\end{array}$ & RS & 45 & Aluvial & Parcelas & 1,0 ha & $\begin{array}{c}\mathrm{CAP} \geq 15 \\
\mathrm{~cm}\end{array}$ & 30 \\
\hline $\begin{array}{l}\text { (J.C. Budke et } \\
\text { al. dados não } \\
\text { publicados) }\end{array}$ & $\mathrm{Bu} 2$ & $\begin{array}{l}\text { Cachoeira } \\
\text { do Sul }\end{array}$ & RS & 48 & Aluvial & Parcelas & 1,0 ha & $\begin{array}{c}\mathrm{CAP} \geq 15 \\
\mathrm{~cm}\end{array}$ & 48 \\
\hline $\begin{array}{l}\text { Waechter \& } \\
\text { Jarenkow } \\
(1998)\end{array}$ & Wae & Taim & RS & 7 & Paludoso & Quadrantes & 30 pontos & $\begin{array}{c}\mathrm{CAP} \geq \\
15,71 \mathrm{~cm}\end{array}$ & 12 \\
\hline
\end{tabular}

localizadas em regiões de planalto no Sudeste do Brasil. Em um estudo de Rodrigues \& Nave (2000) sobre a composição florística de florestas ciliares do Brasil extraamazônico, incluindo florestas paludosas do Estado de São Paulo, houve resultado similar, com as florestas paludosas formando um único grupo, com pouca diferenciação entre si.

O eixo 1 (figura 2) apresentou auto-valor de 0,6057, que é considerado elevado em florestas tropicais. Isso indica que ocorre elevada substituição de espécies entre as áreas estudadas. As florestas aluviais, sujeitas a inundações temporárias, apresentaram elevada diferenciação em relação ao eixo 1 e ao eixo 2 da DCA. Essa diferenciação está relacionada a dois fatores: a amplitude geográfica abrangida e os diferentes históricos de regime de enchentes e encharcamento (tempo de alagamento, periodicidade de alagamento, características físicas e químicas da água e dos sedimentos, velocidade da água do rio e quantidade de sedimentos depositados, etc.) resultando em diferentes composições florísticas, mesmo em áreas geográficas próximas. Como exemplo disso pode-se indicar as áreas aluviais do Estado de Minas Gerais, que apresentaram maiores diferenciações nos eixos 1 e 2 da DCA do que as florestas paludosas.

O eixo 1 da DCA diferenciou dois principais grupos: 1) florestas paludosas (inundação permanente), com exceção da floresta paludosa do Rio Grande do Sul (Wae), à esquerda do gráfico e 2) florestas aluviais (inundações temporárias) dos Estados do Paraná e Rio Grande do Sul, à direita do gráfico. Na região central do gráfico há um gradiente entre esses dois grupos, em que estão presentes algumas áreas estudadas de 


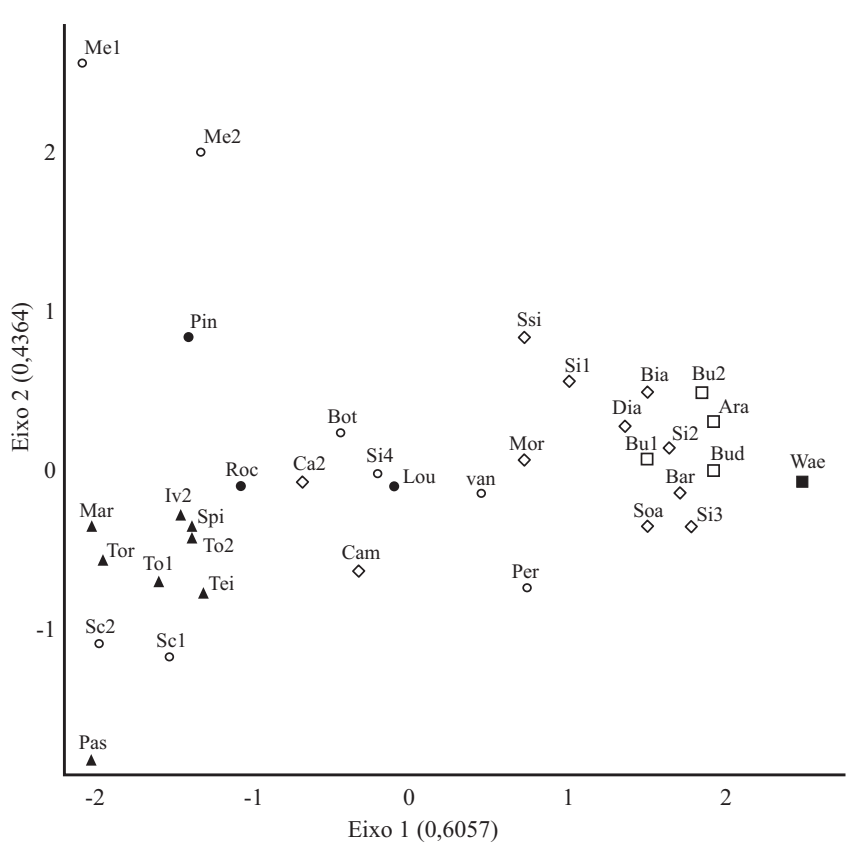

Figura 2. Ordenação das 35 áreas de florestas inundáveis nos dois primeiros eixos da análise de correspondência retificata (DCA). Símbolos preenchidos são florestas paludosas e símbolos vazados são florestas aluviais. Os círculos correspondem às florestas do Estado de Minas Gerais, triângulos às do Estado de São Paulo, losangos às do Estado do Paraná e quadrados às do Estado do Rio Grande do Sul.

Figure 2. Ordination of the 35 wetland forests areas arranged in the first two axes of the Detrended Correspondence Analysis (DCA). Full symbols represent the swamp forests and open symbols represent the alluvial forests. Circles are the areas located in Minas Gerais state, triangles are the areas in São Paulo state, losangle are the areas in Paraná state and squares are the areas in Rio Grande do Sul state.

$\mathrm{Sc} 1=$ Schiavini 1992, area 1; Sc2 = Schiavini 1992, area 2; Me1 = Meira Neto et al. 1997; Me2 = Meira Neto et al. 2003; Roc = Rocha et al. 2005; Pin = Pinto et al. 2005; Bot = Botrel et al. 2002; van $=$ E. van den Berg et al. data not published; Lou = Loures 2006; Si4 = Silva (2007); Per = Pereira et al. 2006; Mar = Marques et al. 2003; Pas = Paschoal \& Cavassan 1999; Tei = Teixeira \& Assis 2005; Iv2 = Ivanauskas et al. 1997; Tor = Torres et al. 1994; Spi $=$ Spina $1997 ;$ To $1=$ Toniato et al .1998 , area $1 ;$ To $2=$ Toniato et al. 1998, area 2; Ca2 = Campos et al. 2000; Cam $=$ Campos \& Souza 2002; Soa = Soares \& Anjos 1997; Bia = Bianchini et al . 2003; Ssi = Soares-Silva et al. 1 1992; Si1 = Silva et al. 1995; Si2 = Silva et al. 1992; Dia = Dias et al. 1998; Mor = Moro et al. 2001; Bar $=$ Barddal et al. $2004 ;$ Si3 = Silva et al $.1997 ;$ Bud $=$ Budke et al. 2004; Ara = Araújo et al. 2004; Bu1 = Budke et al. 2007; Bu2 $=$ J.C. Budke et al . data not published; Wae $=$ Waechter $\&$ Jarenkow 1998. florestas aluviais (inundações temporárias) de Minas Gerais (Bot, Si4, van e Per) e do Rio Paraná (Ca2 e Cam) e a paludosa (inundação permanente) localizada em Santa Rita de Caldas (Lou), Minas Gerais. A floresta paludosa de Santa de Rita de Caldas não participou do agrupamento das florestas paludosas, provavelmente, devido à maior altitude (média de $1.181 \mathrm{~m}$ ). Em Santa Rita de Caldas ocorreram espécies típicas de floresta paludosa, como Magnolia ovata e Dendropanax cuneatus, porém, também foram encontradas espécies típicas de altitude mais elevadas e de regiões mais frias, como por exemplo, Ilex paraguariensis A. St.-Hil. A área aluvial de Bocaina de Minas (Per), Minas Gerais, esteve próxima às áreas da região Sul do país, na DCA, provavelmente devido também à maior altitude desta região mineira $(1.135 \mathrm{~m})$.

As áreas aluviais de Viçosa (Me2) e Ponte Nova (Me1), localizadas na zona da mata mineira e em uma bacia hidrográfica distinta - bacia do Atlântico Sul, trecho Leste (figura 1) - diferenciaram-se bastante no eixo 2 da DCA. Esse resultado reforça a idéia de bacias hidrográficas como unidades ambientais. Rodrigues \& Nave (2000) também verificaram que as florestas ciliares pertencentes a bacias hidrográficas distintas foram reunidas em grupos diferentes. As florestas paludosas de Lavras (Pin), MG e Agudos (Pas), SP, também se diferenciaram no eixo 2 da DCA, talvez devido a fatores relacionados ao histórico de perturbação ou fatores edáficos. Mas essa afirmação requer estudos comparativos mais precisos para permitir inferências mais seguras.

A ocorrência de espécies arbóreas vegetais em áreas inundáveis pode seguir vários padrões de distribuição geográfica. Luehea divaricata foi a espécie encontrada com maior freqüência nas áreas inundáveis estudadas, com ocorrência em 21 das 35 áreas, possuindo ampla distribuição nas regiões Sul e Sudeste do Brasil (figura 3). Já Rodrigues \& Nave (2000), em um trabalho de comparação florística de florestas ciliares, encontraram Cecropia pachystachya na maioria das florestas estudadas (65,11\% das áreas). Neste estudo, Cecropia pachystachya obteve também uma alta ocorrência, em 16 áreas das 35 estudadas $(45,7 \%)$.

Outras espécies com ampla distribuição tanto na região Sul como Sudeste são: Syagrus romanzoffiana, que teve ocorrência em 20 áreas das 35 estudadas (figura 3), Vitex megapotamica e Casearia sylvestris, ambas com ocorrência em 18 áreas. Já Copaifera langsdorffii (figura 3) e Prunus myrtifolia ocorreram em 17 áreas localizadas em Minas Gerais, São Paulo e Paraná, sem ocorrência no Estado do Rio Grande do Sul. Tapirira 

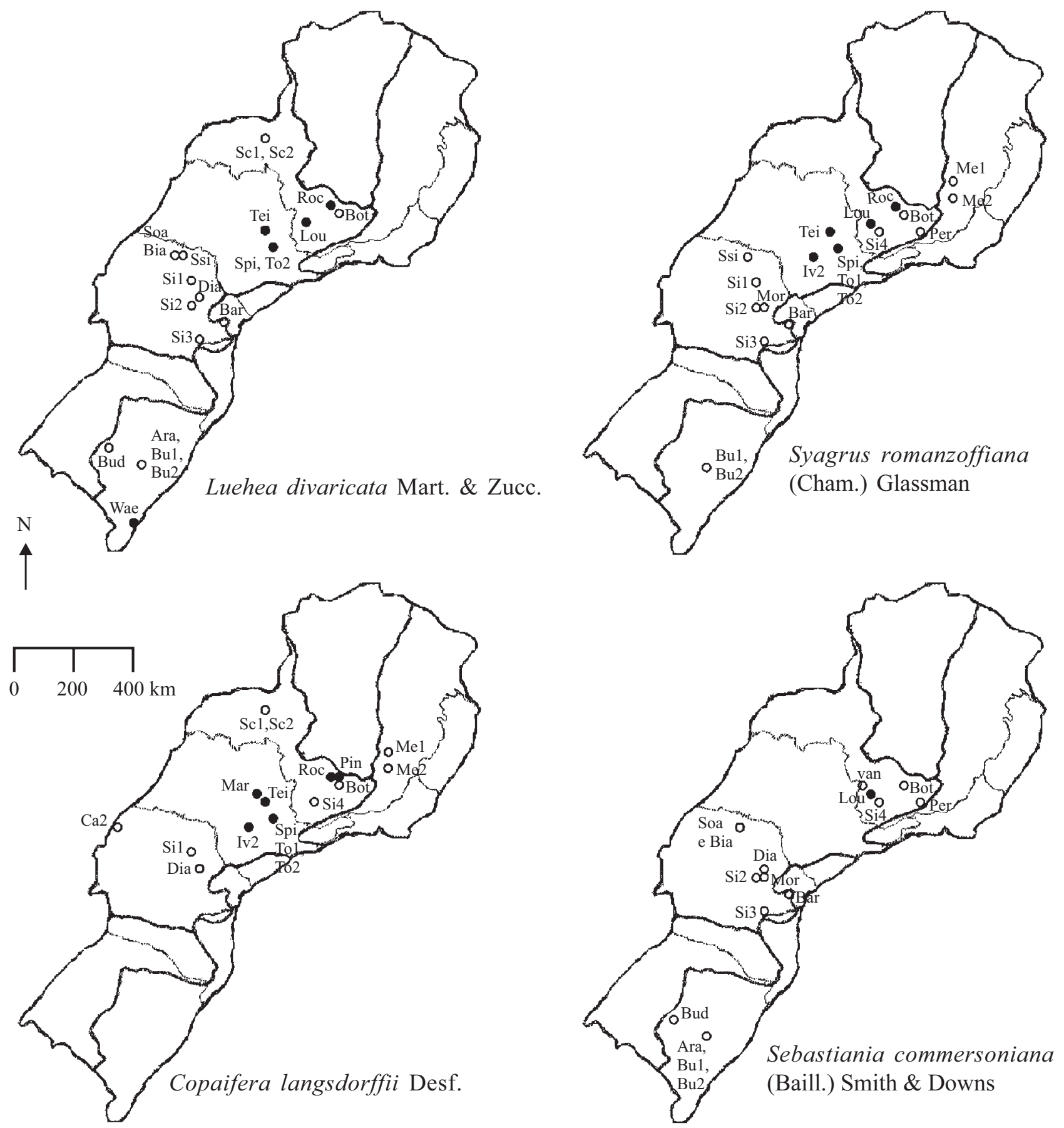

Figura 3. Distribuição geográfica de Luehea divaricata, Syagrus romanzoffiana, Copaifera langsdorffii e Sebastiania commersoniana. Círculos preenchidos correspondem a áreas de florestas paludosas, círculos vazados são florestas aluviais.

Figure 3. Geographic distribution of Luehea divaricata, Syagrus romanzoffiana, Copaifera langsdorffii and Sebastiania commersoniana. Full circles represent the swamp forest areas and open circles are the alluvial forest areas.

Sc1 = Schiavini 1992, area 1; Sc2 = Schiavini 1992, area 2; Me1 = Meira Neto et al. $1997 ;$ Me2 = Meira Neto et al. $2003 ;$ Roc $=$ Rocha et al. 2005; Pin = Pinto et al. 2005; Bot = Botrel et al. 2002; van = E. van den Berg et al . data not published; Lou = Loures 2006; Si4 = Silva 2007; Per = Pereira et al. 2006; Mar = Marques et al. 2003; Tei = Teixeira \& Assis 2005; Iv2 = Ivanauskas et al. 1997; Spi = Spina 1997; To1 $=$ Toniato et al . 1998, area 1; To2 = Toniato et al. 1998, area 2; Ca2 = Campos et al. 2000; Soa = Soares \& Anjos 1997; Bia = Bianchini et al. 2003; Ssi = Soares-Silva et al. 1992; Si1 = Silva et al. 1995; Si2 = Silva et al. 1992; Dia = Dias et al. 1998; Mor = Moro et al. 2001; Bar $=$ Barddal et al. 2004; Si3 = Silva et al. 1997; Bud = Budke et al. 2004; Ara = Araújo et al. 2004; Bu1 = Budke et al. 2007; Bu2 = J.C. Budke et al. data not published; Wae = Waechter \& Jarenkow 1998. 
guianensis, Sebastiania commersoniana e Cecropia pachystachya ocorreram em 16 áreas das 35 estudadas. Tapirira guianensis e Cecropia pachystachya obtiveram a mesma distribuição de Copaifera langsdorffii e Prunus myrtifolia, sem ocorrência no Rio Grande do Sul. Oliveira Filho \& Ratter (2000) também demonstraram a não ocorrência de Tapirira guianensis no Rio Grande do Sul. Sebastiania commersoniana, ao contrário, ocorreu somente em regiões mais frias, no sul do país e em regiões altas no Sul de Minas Gerais, ocorrendo quase exclusivamente em florestas aluviais, sendo registrada para floresta paludosa apenas em Santa Rita de Caldas (Minas Gerais), onde a altitude é maior. Períodos glaciais recentes durante o Pleistoceno podem explicar o padrão de distribuição fitogeográfico disjunto, como o da Sebastiania commersoniana. Durante aquele período, o clima da região era mais frio e seco, sendo que algumas espécies apresentavam populações com ampla distribuição geográfica (Brown Junior \& Ab'Saber 1979, Van der Hammen 1982, Burham \& Graham 1999, Oliveira et al. 2005). Entretanto, com a mudança do clima para mais quente e úmido, as populações se contraíram, ficando restritas ao Sul e regiões altas do Sudeste (Brown Junior \& Ab'Saber 1979, Van der Hammen 1982, Burnham \& Graham 1999, Oliveira et al. 2005).

Walter \& Ribeiro (1997) separaram as espécies arbóreas em três grupos: i) indiferentes (ou generalistas sensu Marques et al. 2003), espécies que podem ocorrer em áreas alagadas e não alagadas; ii) preferenciais, espécies que ocorrem mais freqüentemente no ambiente alagado ou no bem drenado e iii) exclusivas, espécies que ocorrem somente em um dos ambientes, ou no bem drenado, ou no alagado. Neste estudo com florestas inundáveis, foi comum a ocorrência de Tapirira guianensis, Copaifera langsdorffii, Cecropia pachystachya, Casearia sylvestris, Ocotea pulchella, Myrsine umbellata e Pera glabrata, espécies consideradas generalistas de hábitat por Marques et al. (2003). Espécies preferenciais de ambientes bem drenados (sensu Marques et al. 2003) também ocorreram nas florestas inundáveis analisadas, porém, de forma pouco freqüente. Entre elas estão: Styrax pohlii, Acacia polyphylla, Roupala montana, Duguetia furfuracea (A. St.-Hil.) Benth. \& Hook., Xylopia aromatica Lam., Vochysia tucanorum Mart., Machaerium acutifolium Vogel, Machaerium brasiliense Vogel e Virola sebifera Aubl. As espécies classificadas, segundo Marques et al. (2003), como preferenciais de solo encharcado, e que ocorreram com bastante freqüência nas áreas estudadas, são: Dendropanax cuneatus, Protium spruceanum,
Calophyllum brasiliense, Sebastiania brasiliensis, Magnolia ovata e Guarea macrophylla. Marques et al. (2003) afirmam que espécies generalistas e de solo drenado aumentam a riqueza da floresta inundada, enquanto que as espécies de solo encharcado são importantes, principalmente, na definição da dominância e densidade.

Dentre as espécies que Lobo \& Joly (2000) consideram como tolerantes ao alagamento, e que ocorreram nas áreas estudadas, estão: Sebastiania commersoniana, Calophyllum brasiliense, Ceiba speciosa (A. St.-Hil.) Ravenna, Copaifera langsdorffii, Genipa americana L., Hymenaea courbaril L., Inga vera e Magnolia ovata. Apesar de também poderem ocorrer em ambientes sem inundação, algumas dessas espécies são mais abundantes em ambientes inundáveis. Desvantagens competitivas podem explicar a ausência ou pouca ocorrência das espécies adaptadas a ambientes alagados em áreas bem drenadas das formações florestais adjacentes, apesar da maioria das espécies crescer bem quando cultivada em condições de boa drenagem (Lobo \& Joly 2000).

Neste estudo, as espécies puderam ser separadas em: 1) preferenciais de florestas paludosas; 2) preferenciais de florestas aluviais e 3) espécies não preferenciais. Algumas espécies encontradas preferencialmente nas florestas paludosas foram: Magnolia ovata, Dendropanax cuneatus, Calophyllum brasiliense, Protium spruceanum, Styrax pohlii, Citronella gongonha e Cedrela odorata (tabela 2). Neste trabalho não foram estudados ambientes bem drenados, portanto, a classificação de preferencial em florestas paludosas ou preferencial de florestas aluviais não exclui sua ocorrência em ambientes bem drenados ou em outras formações florestais, pois esta classificação foi baseada apenas na presença e ausência dessas espécies dentro das formações inundáveis, sem ser considerado também seus parâmetros quantitativos. Uma das espécies consideradas por Marques et al. (2003) como de solos bem drenado, Styrax pohlii, está entre as preferenciais de florestas paludosas, o que leva à conclusão de que ela ocorre em ambos ambientes. Porém, não é tolerante a ambientes aluviais que, em geral, possuem também a sedimentação como fator limitante ao estabelecimento de plântulas e os alagamentos que removem a serrapilheira juntamente com o banco de sementes do solo. Da mesma forma ocorre com Protium spruceanum, que pode ser uma espécie dominante em áreas não inundáveis, como na mata de galeria estudada por van den Berg \& Oliveira Filho (2000), e com Cedrela 
Tabela 2. Espécies que ocorreram com maior freqüência nas 35 florestas inundáveis avaliadas. $\mathrm{N}=$ número de áreas em que as espécies ocorreram; $\mathrm{Na}=$ número de áreas de floresta aluvial em que ocorreram as espécies $(n=23) ;(\mathrm{Nb}=$ número de áreas de florestas paludosas em que as espécies ocorreram $(n=12) ; P=$ nível de significância $(\alpha=10 \%)$. Classificação $(\mathrm{C})$ : Pa $=$ espécies preferenciais de floresta aluvial; $\mathrm{Pb}=$ espécies preferenciais de floresta paludosa; $\mathrm{Np}=$ espécies não preferenciais). Os números entre parênteses são os valores esperados de acordo com o teste $\chi^{2}$.

Table 2. Species with higher frequencies of occurrence in the 35 studied wetlands forests. $\mathrm{N}=$ total number of areas where the species was present; $\mathrm{Na}=$ total number of alluvial forests areas where the species was present $(n=23)$; ( $\mathrm{Nb}=$ total number of swamp forest areas where the species was present $(n=12) ; P=\operatorname{significance~level~}(\alpha=10 \%)$. Classification $(\mathrm{C})$ : Pa $=$ alluvial forests species; $\mathrm{Pb}=$ swamp forest species; $\mathrm{Np}=$ non preferential species). The numbers between brackets are the expected values according to the $\chi^{2}$ test.

\begin{tabular}{|c|c|c|c|c|c|c|}
\hline Família & Espécie & $\mathrm{N}$ & $\mathrm{Na}$ & $\mathrm{Nb}$ & $P$ & $\mathrm{C}$ \\
\hline Malvaceae & Luehea divaricata Mart. \& Zucc. & 21 & $15(13,8)$ & $6(7,2)$ & 0,5812 & $\mathrm{~Np}$ \\
\hline Arecaceae & Syagrus romanzoffiana (Cham.) Glassman & 20 & $13(13,1)$ & $7(6,9)$ & 0,9463 & $\mathrm{~Np}$ \\
\hline Lamiaceae & Vitex megapotamica (Spreng.) Moldenke & 18 & $15(11,8)$ & $3(6,2)$ & 0,1153 & $\mathrm{~Np}$ \\
\hline Salicaceae & Casearia sylvestris $\mathrm{Sw}$. & 18 & $15(11,8)$ & $3(6,2)$ & 0,1153 & $\mathrm{~Np}$ \\
\hline Fabaceae/Caes. & Copaifera langsdorffii Desf. & 17 & $9(11,2)$ & $8(5,8)$ & 0,2672 & $\mathrm{~Np}$ \\
\hline Rosaceae & Prunus myrtifolia (L.) Urb. & 17 & $10(11,2)$ & $7(5,8)$ & 0,5495 & $\mathrm{~Np}$ \\
\hline Anacardiaceae & Tapirira guianensis Aubl. & 16 & $6(10,5)$ & $10(5,5)$ & 0,0174 & $\mathrm{~Pb}$ \\
\hline Euphorbiaceae & Sebastiania commersoniana (Baill.) L.B. Sm. \& Downs & 16 & $15(10,5)$ & $1(5,5)$ & 0,0182 & $\mathrm{~Pa}$ \\
\hline Urticaceae & Cecropia pachystachya Trécul & 16 & $7(10,5)$ & $9(5,5)$ & 0,0642 & $\mathrm{~Pb}$ \\
\hline Lauraceae & Ocotea pulchella Mart. & 15 & $13(9,9)$ & $2(5,1)$ & 0,0873 & $\mathrm{~Pa}$ \\
\hline Magnoliaceae & Magnolia ovata (A. St.-Hil.) Spreng. & 15 & $4(9,9)$ & $11(5,1)$ & 0,0014 & $\mathrm{~Pb}$ \\
\hline Salicaceae & Casearia decandra Jacq. & 15 & $13(9,9)$ & $2(5,1)$ & 0,0873 & $\mathrm{~Pa}$ \\
\hline Araliaceae & Dendropanax cuneatus (DC.) Decne \& Planch. & 14 & $3(9,2)$ & $11(4,8)$ & 0,0005 & $\mathrm{~Pb}$ \\
\hline Lauraceae & Ocotea diospyrifolia (Meisn.) Mez & 14 & $9(9,2)$ & $5(4,8)$ & 0,9103 & $\mathrm{~Np}$ \\
\hline Meliaceae & Guarea macrophylla Vahl & 14 & $7(9,2)$ & $7(4,8)$ & 0,2155 & $\mathrm{~Np}$ \\
\hline Moraceae & Sorocea bonplandii (Baill.) W. Burger et al. & 14 & $13(9,2)$ & $1(4,8)$ & 0,0324 & $\mathrm{~Pa}$ \\
\hline Sapotaceae & Chrysophyllum marginatum (Hook. \& Arn.) Radlk. & 14 & $11(9,2)$ & $3(4,8)$ & 0,3108 & $\mathrm{~Np}$ \\
\hline Clusiaceae & Calophyllum brasiliense Cambess. & 13 & $5(8,5)$ & $8(4,5)$ & 0,0384 & $\mathrm{~Pb}$ \\
\hline Euphorbiaceae & Sebastiania brasiliensis Spreng. & 13 & $10(8,5)$ & $3(4,5)$ & 0,3945 & $\mathrm{~Np}$ \\
\hline Sapindaceae & Cupania vernalis Cambess. & 13 & $12(8,5)$ & $1(4,5)$ & 0,0434 & $\mathrm{~Pa}$ \\
\hline Sapindaceae & Matayba elaeagnoides Radlk. & 13 & $13(8,5)$ & $0(4,5)$ & 0,0092 & $\mathrm{~Pa}$ \\
\hline Annonaceae & Rollinia emarginata Schltdl. & 12 & $11(7,9)$ & $1(4,1)$ & 0,0582 & $\mathrm{~Pa}$ \\
\hline Euphorbiaceae & Gymnanthes concolor (Spreng.) Müll. Arg. & 12 & $11(7,9)$ & $1(4,1)$ & 0,0582 & $\mathrm{~Pa}$ \\
\hline Myrtaceae & Blepharocalyx salicifolius (Kunth) O. Berg & 12 & $9(7,9)$ & $3(4,1)$ & 0,4980 & $\mathrm{~Np}$ \\
\hline Myrtaceae & Calyptranthes concinna DC. & 12 & $9(7,9)$ & $3(4,1)$ & 0,4980 & $\mathrm{~Np}$ \\
\hline Myrtaceae & Myrciaria tenella (DC.) O. Berg & 12 & $11(7,9)$ & $1(4,1)$ & 0,0582 & $\mathrm{~Pa}$ \\
\hline Euphorbiaceae & Sapium glandulosum (L.) Morong & 11 & $8(7,2)$ & $3(3,8)$ & 0,6241 & $\mathrm{~Np}$ \\
\hline Fabaceae/Fab. & Machaerium hirtum (Vell.) Stellfeld & 11 & $5(7,2)$ & $6(3,8)$ & 0,1569 & $\mathrm{~Np}$ \\
\hline Fabaceae/Mimos. & Inga vera Willd. & 11 & $10(7,2)$ & $1(3,8)$ & 0,0783 & $\mathrm{~Pa}$ \\
\hline Lauraceae & Endlicheria paniculata (Spreng.) Macbr. & 11 & $7(7,2)$ & $4(3,8)$ & 0,8846 & $\mathrm{~Np}$ \\
\hline Meliaceae & Trichilia pallida Sw. & 11 & $6(7,2)$ & $5(3,8)$ & 0,4352 & $\mathrm{~Np}$ \\
\hline Myrtaceae & Eugenia uniflora L. & 11 & $11(7,2)$ & $0(3,8)$ & 0,0166 & $\mathrm{~Pa}$ \\
\hline Myrtaceae & Myrcia laruotteana Cambess. & 11 & $5(7,2)$ & $6(3,8)$ & 0,1569 & $\mathrm{~Np}$ \\
\hline Myrtaceae & Myrcia multiflora (Lam.) DC. & 11 & $9(7,2)$ & $2(3,8)$ & 0,2605 & $\mathrm{~Np}$ \\
\hline Rubiaceae & Guettarda viburnoides Cham. \& Schltdl. & 11 & $10(7,2)$ & $1(3,8)$ & 0,0783 & $\mathrm{~Pa}$ \\
\hline Sapindaceae & Allophylus edulis (A. St.-Hil. et al.) Radlk. & 11 & $10(7,2)$ & $1(3,8)$ & 0,0783 & $\mathrm{~Pa}$ \\
\hline Fabaceae/Fab. & Machaerium nyctitans (Vell.) Benth. & 10 & $7(6,6)$ & $3(3,4)$ & 0,7752 & $\mathrm{~Np}$ \\
\hline Myrsinaceae & Myrsine umbellata Mart. & 10 & $6(6,6)$ & $4(3,4)$ & 0,7034 & $\mathrm{~Np}$ \\
\hline Myrtaceae & Campomanesia xanthocarpa O. Berg & 10 & $10(6,6)$ & $0(3,4)$ & 0,0224 & $\mathrm{~Pa}$ \\
\hline Myrtaceae & Eugenia florida DC. & 10 & $5(6,6)$ & $5(3,4)$ & 0,2951 & $\mathrm{~Np}$ \\
\hline Myrtaceae & Myrcia splendens (Sw.) DC. & 10 & $7(6,6)$ & $3(3,4)$ & 0,7752 & $\mathrm{~Np}$ \\
\hline Anacardiaceae & Schinus terebinthifolius Raddi & 9 & $6(5,9)$ & $3(3,1)$ & 0,9520 & $\mathrm{~Np}$ \\
\hline
\end{tabular}


continuação

\begin{tabular}{|c|c|c|c|c|c|c|}
\hline Família & Espécie & $\mathrm{N}$ & $\mathrm{Na}$ & $\mathrm{Nb}$ & $P$ & $\mathrm{C}$ \\
\hline Bignoniaceae & Tabebuia umbellata (Sond.) Sandw. & 9 & $2(5,9)$ & $7(3,1)$ & 0,0058 & $\mathrm{~Pb}$ \\
\hline Burseraceae & Protium spruceanum (Benth.) Engl. & 9 & $1(5,9)$ & $8(3,1)$ & 0,0006 & $\mathrm{~Pb}$ \\
\hline Euphorbiaceae & Alchornea triplinervea (Spreng.) Müll. Arg. & 9 & $5(5,9)$ & $4(3,1)$ & 0,5208 & $\mathrm{~Np}$ \\
\hline Euphorbiaceae & Croton floribundus Spreng. & 9 & $6(5,9)$ & $3(3,1)$ & 0,9520 & $\mathrm{~Np}$ \\
\hline Euphorbiaceae & Pera glabrata (Schott) Poepp. & 9 & $3(5,9)$ & $6(3,1)$ & 0,0407 & $\mathrm{~Pb}$ \\
\hline Fabaceae/Mimos. & Acacia polyphylla DC. & 9 & $7(5,9)$ & $2(3,1)$ & 0,4458 & $\mathrm{~Np}$ \\
\hline Fabaceae/Mimos. & Inga marginata Willd. & 9 & $5(5,9)$ & $4(3,1)$ & 0,5208 & $\mathrm{~Np}$ \\
\hline Loganiaceae & Strychnos brasiliensis (Spreng.) Mart. & 9 & $9(5,9)$ & $0(3,1)$ & 0,0302 & $\mathrm{~Pa}$ \\
\hline Burseraceae & Protium heptaphyllum (Aubl.) Marchand & 8 & $5(5,3)$ & $3(2,7)$ & 0,8481 & $\mathrm{~Np}$ \\
\hline Euphorbiaceae & Alchornea glandulosa Poepp. \& Endl. & 8 & $5(5,3)$ & $3(2,7)$ & 0,8481 & $\mathrm{~Np}$ \\
\hline Euphorbiaceae & Croton urucurana Baill. & 8 & $6(5,3)$ & $2(2,7)$ & 0,5800 & $\mathrm{~Np}$ \\
\hline Fabaceae/Caes. & Apuleia leiocarpa (Vogel) Macbr. & 8 & $8(5,3)$ & $0(2,7)$ & 0,0411 & $\mathrm{~Pa}$ \\
\hline Fabaceae/Fab. & Machaerium paraguariense Hassl. & 8 & $8(5,3)$ & $0(2,7)$ & 0,0411 & $\mathrm{~Pa}$ \\
\hline Lauraceae & Nectandra megapotamica (Spreng.) Mez & 8 & $8(5,3)$ & $0(2,7)$ & 0,0411 & $\mathrm{~Pa}$ \\
\hline Lauraceae & Ocotea indecora (Schott) Mez & 8 & $7(5,3)$ & $1(2,7)$ & 0,1942 & $\mathrm{~Np}$ \\
\hline Meliaceae & Guarea kunthiana A. Juss. & 8 & $4(5,3)$ & $4(2,7)$ & 0,3491 & $\mathrm{~Np}$ \\
\hline Proteaceae & Roupala montana Aubl. & 8 & $5(5,3)$ & $3(2,7)$ & 0,8481 & $\mathrm{~Np}$ \\
\hline Polygonaceae & Ruprechtia laxiflora Meisn. & 8 & $8(5,3)$ & $0(2,7)$ & 0,0411 & $\mathrm{~Pa}$ \\
\hline Styracaceae & Styrax pohlii A. DC. & 8 & $0(5,3)$ & $8(2,7)$ & 0,0000 & $\mathrm{~Pb}$ \\
\hline Cardiopteridaceae & Citronella gongonha (Miers) Howard & 7 & $0(4,6)$ & $7(2,4)$ & 0,0002 & $\mathrm{~Pb}$ \\
\hline Fabaceae/Fab. & Dalbergia frutescens (Vell.) Britton & 7 & $7(4,6)$ & $0(2,4)$ & 0,0560 & $\mathrm{~Pa}$ \\
\hline Fabaceae/Fab. & Erythrina falcata Benth. & 7 & $5(4,6)$ & $2(2,4)$ & 0,7501 & $\mathrm{~Np}$ \\
\hline Fabaceae/Fab. & Machaerium minutiflorum Tul. & 7 & $6(4,6)$ & $1(2,4)$ & 0,2649 & $\mathrm{~Np}$ \\
\hline Fabaceae/Mimos. & Parapiptadenia rigida (Benth.) Brenan & 7 & $7(4,6)$ & $0(2,4)$ & 0,0560 & $\mathrm{~Pa}$ \\
\hline Lauraceae & Nectandra lanceolata Nees & 7 & $4(4,6)$ & $3(2,4)$ & 0,6328 & $\mathrm{~Np}$ \\
\hline Lauraceae & Nectandra nitidula Nees & 7 & $2(4,6)$ & $5(2,4)$ & 0,0384 & $\mathrm{~Pb}$ \\
\hline Meliaceae & Cabralea canjerana (Vell.) Mart. & 7 & $4(4,6)$ & $3(2,4)$ & 0,6328 & $\mathrm{~Np}$ \\
\hline Meliaceae & Cedrela odorata $\mathrm{L}$. & 7 & $0(4,6)$ & $7(2,4)$ & 0,0002 & $\mathrm{~Pb}$ \\
\hline Meliaceae & Trichilia catigua A. Juss. & 7 & $6(4,6)$ & $1(2,4)$ & 0,2649 & $\mathrm{~Np}$ \\
\hline Myrtaceae & Eugenia uruguayensis Cambess. & 7 & $6(4,6)$ & $1(2,4)$ & 0,2649 & $\mathrm{~Np}$ \\
\hline Rubiaceae & Randia nitida (Kunth) DC. & 7 & $7(4,6)$ & $0(2,4)$ & 0,0560 & $\mathrm{~Pa}$ \\
\hline Rutaceae & Zanthoxylum rhoifolium Lam. & 7 & $6(4,6)$ & $1(2,4)$ & 0,2649 & $\mathrm{~Np}$ \\
\hline Sapindaceae & Matayba guianensis Aubl. & 7 & $6(4,6)$ & $1(2,4)$ & 0,2649 & $\mathrm{~Np}$ \\
\hline Sapotaceae & Chrysophyllum gonocarpum (Mart. \& Eichler) Engl. & 7 & $5(4,6)$ & $2(2,4)$ & 0,7501 & $\mathrm{~Np}$ \\
\hline
\end{tabular}

odorata, espécie comum na caatinga. Algumas espécies que ocorreram preferencialmente nas florestas aluviais foram: Sebastiania commersoniana, Ocotea pulchella, Casearia decandra, Sorocea bonplandii, Cupania vernalis, Matayba elaeagnoides, Gymnanthes concolor, Rollinia emarginata e Myrciaria tenella. Algumas espécies, que não foram preferenciais, ocorrendo tanto em florestas paludosas como aluviais, são: Luehea divaricata, Syagrus romanzoffiana, Copaifera langsdorffii, Ocotea diospyrifolia e Guarea macrophylla (tabela 2). Alguns desses resultados foram observados por Lobo \& Joly (2000), que relataram que espécies típicas dos diques (inundações temporárias), como por exemplo, Inga vera, raramente ocorrem nas depressões atrás dos diques ou em florestas paludosas (inundações permanentes), e espécies típicas das florestas paludosas, como Magnolia ovata e Calophyllum brasiliense, raramente ocorrem em florestas aluviais.

O presente estudo fornece uma contribuição para o entendimento fitogeográfico de áreas inundáveis das regiões Sudeste e Sul do Brasil. Áreas com regime de inundação semelhantes e próximas geograficamente tenderam a estar mais próximas nos eixos de ordenação da DCA, o que permitiu a identificação de dois grupos floristicamente distintos, representados pelas florestas paludosas e florestas aluviais. O grupo formado pelas florestas paludosas é mais homogêneo e com menor riqueza de espécies do que o grupo formado pelas florestas aluviais. A diferença entre estes dois grupos é 
evidenciada pela elevada substituição de espécies entre as áreas estudadas, em função do grande número de espécies preferenciais e das diferenças climáticas relacionadas à abrangência da área geográfica abordada.

Ao assumir que as florestas inundáveis podem ser agrupadas em duas classes distintas, sugere-se que planos de manejo que visem à conservação e restauração desses ambientes devam também considerar a heterogeneidade ambiental associada aos diferentes regimes de inundação.

No presente trabalho, um dos fatores limitantes para conclusões mais categóricas foi a escassez de estudos em áreas inundadas, visto não terem sido encontrados estudos publicados em florestas paludosas no Estado do Paraná e em florestas aluviais no Estado de São Paulo e em aluviais ou paludosas no estado de Santa Catarina.

Dada a natureza complexa das relações ecológicas que determinam os padrões fitogeográficos, são necessários trabalhos futuros em que sejam identificadas e quantificadas suas relações com variáveis ambientais (por exemplo, climáticas e edáficas) para maior entendimento das variações florísticas de florestas inundáveis.

Agradecimentos - Ao pesquisador Jean C. Budke, da Universidade Federal do Rio Grande do Sul, pela gentileza de fornecer seus dados da área de Cachoeira do Sul - RS.

\section{Referências bibliográficas}

APG II. 2003. An update of the Angiosperm Phylogeny Group classification for the orders and families of flowering plants: APG II. Botanical Journal of the Linnean Society 141:399-436.

ARAUJO, M.M., LONGHI, S.J., BRENA, D.A., BARROS, P.L.C. \& FRANCO, S. 2004. Análise de agrupamento da vegetação de um fragmento de floresta estacional decidual aluvial, Cachoeira do Sul, RS, Brasil. Ciência Florestal 14:133-147.

BARDDAL, M.L., RODERJAN, C.V., GALVÃO, F. \& CURCIO, G.R. 2004. Caracterização florística e fitossociológica de um trecho sazonalmente inundável de floresta aluvial, em Araucária, PR. Ciência Florestal 14:37-50.

BIANCHINI, E., POPOLO, R.S., DIAS, M.C. \& PIMENTA, J.A. 2003. Diversidade e estrutura de espécies arbóreas em área alagável do município de Londrina, sul do Brasil. Acta Botanica Brasilica 17:405-419.

BOTREL, R.,OLIVEIRAFILHO,A.T., RODRIGUES,L.A.\&CURI, N. 2002. Influência do solo e topografia sobre as variações da composição florística e estrutura da comunidade arbóreo-arbustiva de uma floresta estacional semidecidual em Ingaí, MG. Revista Brasileira de Botânica 25:195-213.
BROWN JUNIOR, K.S. \& AB'SÁBER, A.N. 1979. Ice-age forest refuges and evolution in the Neotropics: correlation of paleoclimatological, geomorphological and pedological data with modern biological endemism. Paleoclimas 5:1-30.

BRUMMITT, R.K. \& POWELL, C.E. 1992. Authors of plant names. Royal Botanic Gardens, Kew.

BUDKE, J.C., GIEHL, E.L.H.,ATHAYDE, E.A., EISINGER, S.M. \& ZÁCHIA, R.A. 2004. Florística e fitossociologia do componente arbóreo de uma floresta ribeirinha, arroio Passo das Tropas, Santa Maria, RS, Brasil. Acta Botanica Brasilica 18:581-589.

BUDKE, J.C., JARENKOW, J.A. \& OLIVEIRA FILHO, A.T. 2007. Relationships between tree component structure, topography and soils of a riverside forest, Rio Botucaraí, Southern Brazil. Plant Ecology 189:187-200.

BURNHAM, R.J. \& GRAHAM, A. 1999. The history of Neotropical vegetation: New developments and status. Annals of the Missouri Botanical Garden 86:546-89.

CAMPOS, J.B. \& SOUZA, M.C. 2002. Arboreous vegetation of an alluvial riparian forest and their soils relations: Porto Rico island, Paraná River, Brazil. Brazilian Archives of Biology and Technology 45:137-149.

CAMPOS, J.B., ROMANOLO, M.B. \& SOUZA, M.C. 2000. Structure, composition and spatial distribution of tree species in a remnant of the semideciduos seasonal alluvial forest of the upper Paraná river floodplain. Brazilian Archives of Biology and Technology 43:185-194.

DIAS, M.C., VIEIRA, A.O.S., NAKAGIMA, J.N., PIMENTA, J.A. \& LOBO, P.C. 1998. Composição florística e fitossociologia do componente arbóreo das florestas ciliares do rio Iapó, na bacia do rio Tibagi, Tibagi, PR. Revista Brasileira de Botânica 21:183-195.

GOTELLLI, N.J. \& COLWELL, R.K. 2001. Quantifying biodiversity: procedures and pitfalls in measurement and comparison of species richness. Ecology Letter 4:379391.

IVANAUSKAS, N.M., RODRIGUES, R.R. \& NAVE,A.G. 1997. Aspectos ecológicos de um trecho de floresta em Itatinga, SP: florística, fitossociologia e seletividade de espécies. Revista Brasileira de Botânica 20:139-153.

JUNK, W.J. 1993. Wetlands of tropical South America. In Wetlands of the world I: inventory, ecology and management (D. Whigham, S. Hejný \& D. Dykyjová, eds.). Dr. W. Junk Publishing, Boston, p.679-739.

LEITÃO FILHO, H.F. 1982. Aspectos taxonômicos das florestas do Estado de São Paulo. In Anais do I Congresso nacional sobre essências nativas, Campos do Jordão. Silvicultura em São Paulo 1:197206.

LOBO, P.C. \& JOLY, C.A. 2000. Aspectos ecofisiológicos da vegetação de mata ciliar do Sudeste do Brasil. In Matas ciliares: conservação e recuperação (R.R. Rodrigues \& H.F. Leitão Filho, eds.). Editora da Universidade de São Paulo, São Paulo, p.143-157. 
LOURES, L. 2006. Variações florísticas e estruturais em um fragmento de floresta paludosa, no Alto-Rio Pardo, em Santa Rita de Caldas, MG. Dissertação de mestrado, Universidade Federal de Lavras, Lavras.

MARQUES, M.C.M., SILVA, S.M. \& SALINO, A. 2003. Florística e estrutura do componente arbustivo-arbóreo de uma floresta higrófila da bacia do rio Jacaré-Pepira, SP, Brasil. Acta Botanica Brasilica 17:495-506.

MCCUNE, B. \& MEFFORD, M.J. 1999. Multivariate analysis of ecological data version 4.14 MjM Software, Gleneden Beach.

MEIRA NETO, J.A.A., SOUZA, A.L., SILVA, A.F. \& PAULA, A. 1997. Estrutura de uma floresta estacional semidecidual aluvial em área diretamente afetada pela usina hidrelétrica de Pilar, Ponte Nova, Zona da Mata de Minas Gerais. Revista Árvore 21:213-219.

MEIRA NETO, J.A.A., RÊGO, M.M., COELHO, D.J.S \& RIBEIRO, F.G. 2003. Origem, sucessão e estrutura de uma floresta de galeria periodicamente alagada em Viçosa-MG. Revista Árvore 27:561-574.

MORO, R.S., SCHMITT, J. \& DIEDRICHS, L.A. 2001. Estrutura de um fragmento da mata ciliar do rio Carácará, Ponta Grossa, PR. Publicatio UEPG - Biological and Health Sciences 7:19-38.

OKSANEN, J., KINDT, R., LEGENDRE, P. \& O'HARA, R.B. 2006. Vegan: Community Ecology Package version 1.82. http://cran.r-project.org/

OLIVEIRA, P.E., BEHLING, H., LEDRU, M.P., BARBERI, M., LABOURIAU, M.L.S., GARCIA, M.J., MEDEANIC, S., BARTH, M., BARROS, M.A. \& YBERT, R.S. 2005. Paleovegetação e paleoclimas do Quaternário do Brasil. In Quaternário do Brasil (C.R.G. Souza, K. Suguio, A.M.S. Oliveira \& P.E. Oliveira, eds.). Holos Editora, Ribeirão Preto, p.52-74.

OLIVEIRAFILHO, A.T. \& FONTES, M.A.L. 2001. Patterns of floristic differentiation among Atlantic Forests in Southeastern Brazil and the influence of climate. Biotropica 32:793-810.

OLIVEIRAFILHO,A.T. \& RATTER, J.A. 2000. Padrões florísticos das matas ciliares da região do Cerrado e a evolução das paisagens do Brasil central durante o quaternário tardio. In Matas ciliares: conservação e recuperação(R.R. Rodrigues \& H.F. Leitão Filho, eds.). Editora da Universidade de São Paulo, São Paulo, p.73-89.

OLIVEIRAFILHO,A.T., TAMEIRÃONETO, E., CARVALHO, W.A.C., WERNECK, M, BRINA, A.E., VIDAL, C.V., REZENDE, S.C. \& PEREIRA, J.A.A. 2005. Análise florística do compartimento arbóreo de áreas de floresta atlântica sensu lato na região das Bacias do Leste (Bahia, Minas Gerais, Espírito Santo e Rio de Janeiro). Rodriguésia 56:185-235.

PASCHOAL, M.E.S \& CAVASSAN, O. 1999. A flora arbórea da mata de brejo do ribeirão do Pelintra, Agudos, SP. Naturalia 24:171-191.
PEREIRA, I.M., OLIVEIRA FILHO, A.T., BOTELHO, S.A., CARVALHO, W.A.C., FONTES, M.A.L., SCHIAVINI, I. \& SILVA, A.F. 2006. Composição florística do compartimento arbóreo de cinco remanescentes florestais do maciço do Itatiaia, Minas Gerais e Rio de Janeiro. Rodriguésia 57:103-126.

PINTO, L.V.A., BOTELHO, S.A., OLIVEIRA FILHO, A.T. \& DAVIDE, A.C. 2005. Estudo da vegetação como subsídio para propostas de recuperação das nascentes da bacia hidrográfica do ribeirão Santa Cruz, Lavras, MG. Revista Árvore 29:775-794.

R DEVELOPMENT CORE TEAM. 2006. R: A language and environment for statistical computing. $\mathrm{R}$ Foundation for Statistical Computing, Vienna, URL http://www.R-project.org.

ROCHA, C.T.V., CARVALHO,D.A., FONTES, M.A.S., OLIVEIRA FILHO,A.T., VANDEN BERG, E. \& MARQUES, J.J.G.S.M. 2005. Comunidade arbórea de um continuum entre floresta paludosa e de encosta em Coqueiral, Minas Gerais, Brasil. Revista Brasileira de Botânica 28:203-217.

RODRIGUES, R.R. \& NAVE, A.G. 2000. Heterogeneidade florística das matas ciliares. In Matas ciliares: conservação e recuperação (R.R. Rodrigues \& H.F. Leitão Filho, eds.). Editora da Universidade de São Paulo, São Paulo, p.45-71.

RODRIGUES, R.R. \& SHEPHERD, G.J. 2000. Fatores condicionantes da vegetação ciliar. In Matas ciliares: conservação e recuperação (R.R. Rodrigues \& H.F. Leitão Filho, eds.). Editora da Universidade de São Paulo, São Paulo, p.101-107.

SCHIAVINI, I. 1992. Estrutura das comunidades arbóreas de mata de galeria da Estação Ecológica do Panga (Uberlândia, MG). Tese de doutorado, Universidade Estadual de Campinas, Campinas.

SILVA, A.C. 2007. Variações do componente arbóreo de fragmentos da floresta aluvial do Médio Sapucaí, Minas Gerais, e padrões fitogeográficos de florestas inundáveis. Tese de doutorado. Universidade Federal de Lavras. Lavras.

SILVA, F.C., FONSECA, E.P., SOARES-SILVA, L.H. \& BIANCHINI, E. 1995. Composição florística e fitossociologia do componente arbóreo das florestas ciliares da bacia do rio Tibagi. 3. Fazenda Bom Sucesso, município de Sapopema, PR. Acta Botanica Brasilica 9:289-302.

SILVA, S.M., SILVA, F.C., VIEIRA, A.O.S., NAKAJIMA, J.N., PIMENTA, J.A. \& COLLI, S. 1992. Composição florística e fitossociologia do componente arbóreo das florestas ciliares da bacia do rio Tibagi, Paraná: 2. Várzea do rio Bitumirim, município de Ipiranga, PR. In Anais do II Congresso Nacional sobre Essências Nativas. Revista do Instituto Florestal 4:192-198.

SILVA, S.M., BRITEZ, R.M., SOUZA, W.S. \& MOTTA, J.T.W. 1997. Levantamento florístico em área de várzea do rio Iguaçu, São Mateus do Sul, PR, Brasil. Arquivos de Biologia e Tecnologia 40:903-914. 
SOARES, F.S. \& ANJOS, L. 1997. Aspectos da fauna e flora da bacia do rio Tibagi. $4^{\circ}$ Relatório Técnico-Científico. Universidade Estadual de Londrina/COPATI/KLABIN, Londrina.

SOARES-SILVA, L.H., BIANCHINI, E., FONSECA, E.P., DIAS, M.C., MEDRI, M.E. \& ZANGARO FILHO, W. 1992. Composição florística e fitossociologia do componente arbóreo das florestas ciliares da bacia do rio Tibagi. 1 . Fazenda Doralice - Ibiporã, PR. In Anais do II Congresso Florestal sobre Essências Nativas. Revista do Instituto Florestal 4:199-206.

SPINA, P.A. 1997. Levantamento florístico de uma mata higrófila na região de Campinas. Dissertação de mestrado, Universidade Estadual de Campinas, Campinas.

TEIXEIRA, A.P. \& ASSIS, M.A. 2005. Caracterização florística e fitossociológica do componente arbustivo-arbóreo de uma floresta paludosa no Município de Rio Claro (SP), Brasil. Revista Brasileira de Botânica 28:467-476.

TONIATO, M.T.Z., LEITÃOFILHO, H.F. \& RODRIGUES, R.R. 1998. Fitossociologia de um remanescente de floresta higrófila (Mata de Brejo) em Campinas, São Paulo. Revista Brasileira de Botânica 21:197-210.
TORRES, R.B., MATTHES, S.A.F. \& RODRIGUES, R.R. 1994. Florística e estrutura do componente arbóreo de mata de brejo em Campinas, SP. Revista Brasileira de Botânica 17:189-194.

VAN DEN BERG, E. \& OLIVEIRA FILHO, A.T. 2000. Composição florística e estrutura fitossociológica de uma floresta ripária em Itutinga, MG, e comparação com outras áreas. Revista Brasileira de Botânica 23:231-253.

VAN DER HAMMEN, T. 1982. Palaeoecology of tropical South America. In Biological diversification in the tropics (G.T. Prance, ed.). Columbia University Press, New York, p.60-66.

WAECHTER, J.L. \& JARENKOW, J.A. 1998. Composição e estrutura do componente arbóreo das matas turfosas do Taim, Rio Grande do Sul. Biotemas 11:45-70.

WALTER, B.M.T. \& RIBEIRO, J.F. 1997. Spatial floristic patterns in gallery forests in the Cerrado Region, Brazil. In Proceedings of the international symposium on assessment and monitoring of forests in tropical dry regions with special reference to gallery forests (J. ImañaEncinas \& C. Kleinn, eds.). University of Brasília, Brasília, p.339-349. 